\title{
The Effect of an Accompanying Situation on the Improvement of Students' Sight Reading Skills
}

\author{
ALICE WATKINS \\ 1212 Avondale, Norman, Oklahoma \\ MARIE ADELE HUGHES \\ University of Oklahoma, Norman, Oklahoma
}

\begin{abstract}
The purpose of this study was to investigate the effect that accompanying a tape-recorded soloist has on the ability of music students to sight read vocal and instrumental accompaniments at the piano. Specifically, the study examined a tape-recorded accompanying situation and its effects on the accuracy of the following sight reading skills: pitch, rhythm, and expression.

The null hypotheses for the study were tested by the Student's $t$ test (a parametric test), the Mann-Whitney U test (a non-parametric test), and an analysis of covariance (a parametric test). Since the results of all three tests agreed, the validity of the findings was enhanced.

The treatment group that employed a tape-recorded soloist as an aid to teaching sight reading had significantly higher mean posttest rhythm accuracy scores than did the group that employed no taped soloist. The pitch accuracy and expression accuracy mean posttest scores of the two groups were not significantly different.
\end{abstract}

\section{Introduction}

The importance of developing both sight reading and accompanying skills is stressed in the research and writings of several leading music educators (James B. Lyke, 1968; Gillian Buchanan, 1964; and Denes Agay, 1981). For example, Lyke composed a rating scale of 20 important keyboard musicianship items which was administered to general music teachers and class piano teachers throughout the United States. The purpose of Lyke's research was to determine which items should receive high priority in class piano instruction. Both groups noted sight reading as either first or second in importance and the general music teachers ranked sight reading and accompanying in second and third place as the most important skills.

The development of sight reading skills has traditionally been regarded as one of the major functions of piano instruction for non-keyboard music majors. However, despite the recognition given by both classroom teachers and piano teachers to the importance of accompanying, instructional materials used for teaching sight reading skills often do not include accompaniments in the repertoire, and rarely if ever do they involve an accompanying situation. Although some methods of instruction do include accompaniments in their repertoire, they tend to concentrate on the accompaniment part as a solo piece and not as a segment of the whole musical picture.

The purpose of this study was to examine whether incorporating the accompanying of a tape-recorded soloist in classroom instruction would 
improve the ability of music students to sight read vocal and instrumental accompaniments at the piano. Specifically, the study examined the effect on the following sight reading skills: pitch, rhythm, and expression accuracy. There is no previous published research which examines the effect of an accompanying situation on sight reading skills.

The literature on sight reading and accompanying indicate that teaching methods that involve the student in a musical experience result in improved learning. In addition, most authors agree that ensemble experiences are beneficial to the teaching of sight reading skills (Yvonne Enoch, 1978 and Joseph Rezits, 1972). The most obvious advantage is that it forces the student to maintain a steady forward rhythmic flow. In an ensemble situation, the common problem of stopping to correct mistakes while sight reading can be eliminated. Some musicians contend that a steady tempo must prevail even at the expense of pitch accuracy. In sight reading, teachers advise students to omit certain notes or simplify the material in some way to maintain a steady tempo. These techniques can prove helpful in accompanying if not abused to the point of losing essential notes. Because most music teachers consider rhythm accuracy to be the basis of good sight reading skills, it is also possible that pitch and expression accuracy skills might be significantly improved by an instructional method that incorporates an accompanying situation.

\section{Method}

\section{Selection of Sample Groups}

The study was conducted at a university where the class piano programme consists of a four-semester course of study for non-keyboard music majors. Twenty-four music majors were selected from third-semester piano classes for the experiment. They were randomly assigned to one of two classes during pre-enrolment using a table of random numbers (Deobold B. Van Dalen and William J. Meyer, 1966). Two students dropped the class during the semester leaving a total of 22 students involved with the experiment, 12 students in the control group, and ten students in the experimental group.

Third-semester piano students were selected because they had the prerequisite knowledge and skills required for the experiment. For example, in order to effectively participate in the study, the students needed to be familiar with: note names, intervals, music reading, fingering, major, minor, and modal pentachord scales, major, minor, and modal tetrachord scales, chord types, diatonic chords of the key, staccato and legato styles, pedaling, dynamic indications, tempo indications, phrases, and texture. More advanced students were not employed because of the problem of overcoming established habits.

In order to investigate the effect that accompanying a tape-recorded soloist has on the ability of music students to sight read accompaniments at the piano, an experimental design which permitted the comparison of a taperecorded accompanying situation with a situation involving sight reading an accompaniment without the soloist was used. The independent variable in the experiment was the presence or absence of a taped soloist, and the dependent variables were measures of the piano sight reading skills: pitch, rhythm and expression accuracy. 
Most music educators agree that before a student attempts to sight read a piece of music, the composition should be examined closely (Denes Agay, 1981). Therefore, in this study a preparatory procedure was employed before the student began to play to focus the student's attention on important musical information. Using this discovery learning approach, the student became actively involved by thoughtful examination of and response to a set of questions before beginning to play. These questions generally led the student to discover and carefully analyse main characteristics of the composition. All three aspects examined in this study (pitch, rhythm, and expression) were incorporated into these questions to enable students to prepare for all three equally. This procedure was designed to aid in a better understanding of the accompaniment and stimulate active involvement in the process. Each student's (in both groups) answers were written on a form provided by the instructor. The student was given a study period to analyse each component of the checklist. Students in both the control group and the experimental group were directed to employ the prescribed preparatory procedure.

After all the questions on the preparatory procedure had been analysed and answered, the student was then directed to silently read through the work. This allowed the student to identify any problems unique to him/her which could be confronted before the actual performance. One pedagogical approach used with both the control and experimental groups involved the student actually playing parts or sections of the piece silently on the keyboard without depressing the keys. This was just one more way the student could locate trouble spots before beginning to actually play.

The researcher taught both classes in an electronic piano lab and the same lesson plans and materials were used for both classes. Pitch, rhythm, and expression accuracy skills were emphasised equally; the students were never advised to emphasise any one skill at the expense of another. Full details of the lesson plans used, a copy of the preparatory procedure questions, and all instructional compositions used may be obtained by writing to the first author. The taped soloist, which was used only for the experimental group, was recorded at two different tempos (slower than indicated and as indicated) to aid with the instruction.

A different accompaniment was taught to both classes each week of the ten-week experiment. In consultation with members of the music faculty at the University, these examples were selected from the accompaniments listed in standard group piano texts and collections and from the widely used Music Educators National Conference list of vocal and instrumental repertoire for high-school students. The musical selections which were used represented varied textures and styles. The selections were deliberately chosen from different idioms and varied styles to be interesting enough to motivate students from both groups equally. For example, the selection taught the first week of the experiment was an excerpt from Beethoven's Violin Sonata, Op. 24, taken from Harmonisation at the Piano by Arthur Frackenpohl. During the seventh week of the experiment the example taught was "The Fool on the Hill" by John Lennon and Paul McCartney, from Popular Flute, arranged by Oran J. Daly. Both of these selections can be found in Appendix A of this paper. 
Fifteen minutes of each class period were devoted to sight reading accompaniments. Since the classes met twice a week, this was considered ample time to teach the two sight reading procedures and develop skill in their use.

In order to increase the precision of measurement of experimental effects and to control for various types of experimental errors that might occur, a before-after (i.e. pretest-posttest) with control experimental design was employed in this study.

The following null hypotheses were tested:

$\mathrm{H}_{1}$ : There will be no significant difference between the average* posttest pitch accuracy scores of the control and experimental groups at the $\cdot 05$ level of significance.

$\mathrm{H}_{2}$ : There will be no significant difference between the average posttest rhythm accuracy scores of the control and experimental groups at the .05 level of significance.

$\mathrm{H}_{3}$ : There will be no significant difference between the average posttest expression accuracy scores of the control and experimental groups at the $\cdot 05$ level of significance.

The alternative hypothesis in each instance was that the accuracy scores would be higher for the experimental than for the control groups. Therefore, one-tailed tests are appropriate to test the hypotheses.

For completeness and because the normality assumption might be questioned due to the relatively small sample size, both the Student's test (a parametric test for which the arithmetic mean is the appropriate statistic) and the Mann-Whitney U test (the non-parametric analog of the Student's t test for which the median is the appropriate statistic) (Wayne W. Daniel, 1978) were used to test the hypotheses.

\section{Administration and Scoring of the Pretest and Posttest}

The researcher administered the pretest at the beginning and the posttest at the end of the ten-week experiment. Tests were given individually, and each student's performance was electronically recorded. Each student was instructed to read the same preparatory procedure used throughout the experiment and carefully answer all questions for this particular example. Ten minutes were allowed for the student to complete this task.

The difficulty level of the two tests was based on what the students would be able to sight read at the beginning and the end of their third semester of class piano. On the bases of consultations with the Co-ordinator of Group Piano and a Professor of Piano at the University, accompaniments at the appropriate levels were selected. These were: Ah! Vous dirai-je, maman by W. A. Mozart for the pretest and Scotch Dance by L. Van Beethoven for the posttest. These examples can be found in Appendix B of this paper.

The same quantitative scoring procedure was employed for both groups to evaluate the sight reading performance of the students. The pretest and

\footnotetext{
*The word "average" is used as a generic term for central location. This is done so that the hypotheses statements will be appropriate for both parametric and non-parametric tests of central location.
} 
posttest were scored by three members of the University piano faculty who provided pitch, rhythm, and expression scores for each student. No information concerning the identity of the performing student was provided; performances were arranged by number on the tape. These adjudicators evaluated each student based on the number and type of errors that each student made on the test; the highest score represented no errors. To simplify comparison of the pretest and posttest scores, the raw scores were transformed to percentages by dividing each score by the maximum number possible for each measure. The percentage scores were then used in all statistical tests. This transformation does not affect the statistical test results. For a complete description of the scoring procedure see Appendix C.

For each sight reading skill, inter-rater reliability among the three adjudicators on both pretest and posttest scores was examined using Kendall (Wayne W. Daniel, 1978) and Pearson correlation coefficients. The scores were judged to be of sufficient agreement to employ the ratings of the three initial judges in the subsequent analyses.

\section{Results}

\section{Preliminary Analyses}

Because piano skills vary from student to student, not every student was expected to play the piece at the exact tempo established by the examiner. Therefore, a five point tempo scale was recorded on both the pretest and posttest scoring sheets for adjudicators to indicate the extent of deviation from the indicated tempo.

A test was performed to determine whether the average ability of students in the two groups to play at the indicated tempo was equal. For both the pretest and posttest there was no significant difference. Therefore, the extent of deviation from the indicated tempo was judged not to be a factor in analysing the scores.

The pretest was administered immediately following the formation of the control and experimental groups. The purpose of the pretest was to determine whether statistically significant differences existed between the control and experimental groups in average achievement levels with respect to accuracy in pitch, rhythm, and expression. Since both groups were exposed to the same pretest, any changes in dependent variables for each group caused by this premeasurement should have influenced both groups equally. Thus, the design employed in this study controlled for the direct premeasurement effects of the pretest.

If the control and experimental groups are not initially equivalent in achievement, the comparison of posttest scores could be misleading as an indication of changes in achievement over the experiment. Therefore, the percentage scores were analysed by the Student's $t$ test and the MannWhitney $U$ test for equivalence of initial groups. Table I presents the means and standard deviations for the pretest and posttest ratings for the three.

Table II presents the results of the Student's $t$ tests and the Mann-Whitney $\mathrm{U}$ tests for determining the significance of the differences between sample averages for the control and experimental groups. 
TABLE I

Summary of Pretest and Posttest Scores

\begin{tabular}{lcccc}
\hline & \multicolumn{2}{c}{ Control Group } & \multicolumn{2}{c}{ Experimental Group } \\
& Mean & Std. Dev. & Mean & Std. Dev. \\
Pretest & & & & \\
Pitch & .814 & .211 & .860 & .206 \\
Rhythm & .715 & .230 & .767 & .123 \\
Expression & .406 & .169 & .446 & .166 \\
Posttest & & & & \\
Pitch & .847 & .109 & .890 & .078 \\
Rhythm & .668 & .216 & .849 & .068 \\
Expression & .515 & .175 & .553 & .138 \\
\hline
\end{tabular}

TABLE II

Tests of Differences Between Control and Experimental Groups

\begin{tabular}{lcccccc}
\hline & \multicolumn{3}{c}{ Student's $t$} & \multicolumn{2}{c}{ Mann-Whitney $U$} \\
& $t$ & DF & p-value & $z$ & $p$-value \\
Pretest & & & & & \\
Pitch & -0.5082 & 20 & .6169 & -0.6264 & .5378 \\
Rhythm & -0.6395 & 20 & .5297 & -0.3300 & .7447 \\
Expression & -0.5527 & 20 & .5866 & -0.7624 & .4543 \\
Posttest & & & & & & \\
Pitch & & & & & & \\
Rhythm & -0.7774 & 20 & .2230 & -0.6268 & .2688 \\
Expression & -2.5417 & 20 & .0097 & -2.2761 & .0167 \\
& -0.5607 & 20 & .2906 & -0.7587 & .2283 \\
\hline
\end{tabular}

The results of analysing the pretest percentage scores by both parametric and non-parametric tests showed the control and experimental groups to be initially equivalent in average achievement for pitch accuracy, rhythm accuracy, and expression accuracy.

\section{Univariate Posttest Comparisons}

The statistical summary of both the control and experimental groups' posttests using both the Student's t test and the Mann-Whitney U test are presented in Table II.

The .05 level of significance was selected for use in this phase of the analysis. Both tests showed no statistically significant differences in the average pitch accuracy and expression accuracy scores on the posttest. However, for the rhythm accuracy scores, the one-tailed probability value of .0097 on the $t$ test and $\cdot 0167$ on the $U$ test indicated a significantly higher average value for the experimental group's rhythm accuracy scores. 


\section{Comparisons Utilising Adjusted Posttest Scores}

Since the statistical power of the tests for differences was low due to the small sample size, a test of adjusted differences was also performed. This test, an analysis of covariance, is a more stringent test of differences in that it statistically adjusts each of the posttest scores for any variation that may result from initial achievement levels in the corresponding pretest measure. In effect, analysis of covariance statistically adjusts for existing initial differences between the control and experimental and increases the precision of estimation by reducing error variance.

In the analysis of covariance, the dependent variable was the posttest score. The two independent variables were group membership (control or experimental), which is the variable of interest in the experiment, and the pretest score, which was used as a covariate.

Table III presents two p-values for each of the dependent variables: pitch, rhythm and expression. The p-values in the column titled, Model, represents a comparison of control and experimental groups using both the treatment variable and the covariate; it is provided here for completeness in reporting the results. The p-value in the other column represents a comparison of groups based on each student's posttest score after it has been statistically adjusted for his/her pretest score; these are the appropriate p-values to test the research hypotheses.

\section{TABLE III}

Summary of Analysis of Covariance Results

\begin{tabular}{lccr}
\hline \multicolumn{3}{c}{$p$-values } \\
Variable & Model & Comparison of Groups & \\
Pitch & .0246 & .2853 & NOT SIGNIFICANT \\
Rhythm & .0273 & .0141 & SIGNIFICANT \\
Expression & .6090 & .3292 & NOT SIGNIFICANT \\
\hline
\end{tabular}

The analysis of covariance supported the previous findings. That is, statistically significant difference in achievement skills was found between the experimental and control groups only for rhythm.

\section{Discussion}

For this study, we can be relatively confident that a replication that employed a larger sample size would confirm a statistically significant difference in students' rhythm accuracy skills. The reason for this is that more confidence can be placed in a finding of statistical significance in a smallsample study than in a large-sample study, "because effect size is a measure of the strength of relationship and large effects are more likely to be replicated than small ones" (Sawyer and Peter, 1983, p. 124). The reason for the increased confidence is that the smaller the sample, the larger the effect size must be to be considered statistically significant. 
In contrast, the finding of non-significant differences in pitch and expression skills between the control and experimental groups is equivocal because, due to sample size limitations, the power of the statistical tests to detect an improvement in these skills was relatively low.

Table IV contains power values for three possible effect sizes and two possible significance levels, assuming that the assumptions underlying the Student's $t$ test are met. The values were calculated using a pooled population standard deviation estimated from the obtained sample standard deviation.

TABLE IV

Power of the Student's t Test

\begin{tabular}{ccccc}
\hline Effect Size & \multicolumn{2}{c}{ Pitch } & \multicolumn{2}{c}{ Expression } \\
& $\alpha=.05$ & $\alpha=\cdot 10$ & $\alpha=.05$ & $\alpha=\cdot 10$ \\
.10 & .785 & .875 & .429 & .571 \\
.15 & .978 & .999 & .709 & .819 \\
.20 & .991 & 1.000 & .900 & .950 \\
\hline
\end{tabular}

Since the highest score possible in this experiment represented no errors. and since scores were expressed as percentages, the measures in this experiment are similar to grades given on a test in which a grade of $1.00(100$ per cent) represents the highest possible score. Effect size may thus be evaluated in terms of a typical grading system in which a difference of 10 represents one letter grade.

As can be seen from Table IV, the power of the test to detect differences in pitch of $\cdot 15$ and greater is high; the power for a difference of $\cdot 10$ (approximately one letter grade) is moderate. For example, given the study design, there is a 78.5 per cent probability of detecting true differences of one grade level in students' pitch ability when $\cdot 05$ is used as the level of significance of the test. The power of the test with respect to the measure of expression skill is low except for differences of two grade levels (i.e. effect size of $\cdot 20$ ).

The finding that there was no significant difference between the average posttest pitch and expression accuracy scores of the control and experimental groups must therefore be regarded as ambiguous since the $a$ priori probability of rejecting the null hypothesis when an actual difference of, for example, one grade level exists was not high.

\section{Conclusions}

Careful examination of related literature indicates that rhythm accuracy is an important factor in the sight reading process. It is especially crucial in the sight reading of accompaniments, where the pianist must strive to keep a continuous rhythmic flow to the performance. If the rhythm accuracy skills of class piano students are improved by the method discussed in this paper, then actual accompanying situations might be used effectively in the teaching of sight reading skills to various ages of students.

The practical importance of this research lies in: $(a)$ providing preliminary evidence of the value of the suggested new approach in addressing a problem 
of concern to music educators, and $(b)$ stimulating interest in replication and extension of the research.

Since results concerning pitch and expression accuracy were not conclusive in this study, replicating the study with a larger sample would provide stronger evidence with regard to possible benefits of the proposed teaching method in enhancing those skills.

Investigations using other populations (such as junior high pianists, senior high pianists and collegiate piano majors) and other situations (for example, piano duets) could yield valuable information regarding the generalisability of the study findings.

This study only investigated the effects in a group instruction situation. A study using a tape-recorded soloist in teaching sight reading and accompanying skills in the private piano studio could produce valuable research data on the possible benefits for the private piano teacher.

\section{References}

Agay, Denes (Ed.) (1981). Teaching Piano. New York: Yorktown Music Press, Inc.

Buchanan, Gillian (Summer 1968). Skills of piano performance in the preparation of music educators. Journal of Research in Music Education, 12, 134-138.

Daniel, Wayne W. (1978). Applied Nonparametric Statistics. Boston: Houghton Mifflin.

Enoch, Yvonne (1978). Group Piano Teaching. Oxford: Oxford University Press.

Lyke, James B. (1968). An investigation of class piano programmes in the six state universities of Illinois and recommendations for their improvement. (Doctoral dissertation, Colorado State College.)

Rezits, Joseph (September 1972). Everyone should try ensemble sight reading. Clavier, 11, 34.

Sawyer, Alan G. and Peter, J. Paul (May 1983). The significance of statistically significant tests in marketing research. Journal of Marketing Research, 20, 122-133.

Van Dalen, Deobold and Meyer, William J. (1966). Understanding Educational Research. New York: McGraw-Hill Book Company. 


\section{Appendix A \\ Examples of Accompaniments Used with the Experiment}
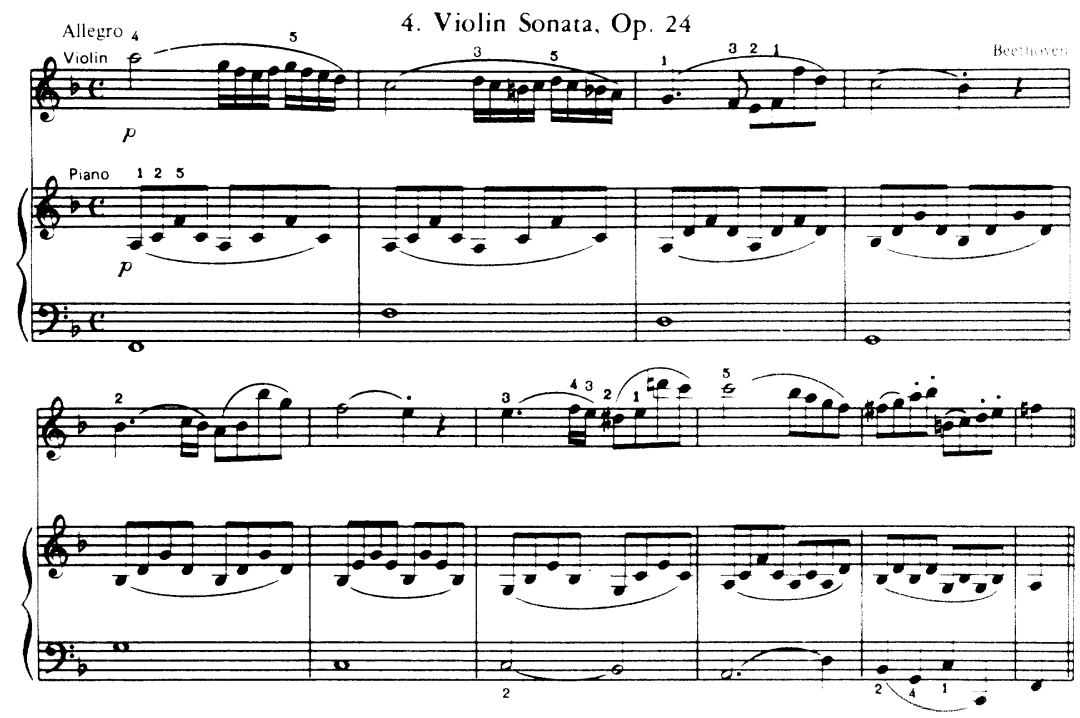

\section{EXAMPLE 1}

"VIOLIN SONATA, Op. 24" (Beethoven) from Harmonisation at the Piano (Third Edition) by Arthur Frackenpohl, p. 91. (C)1977 by William C. Brown

Company Publishers. All rights reserved. Used by permission. 


\section{The Fool On The Hill}
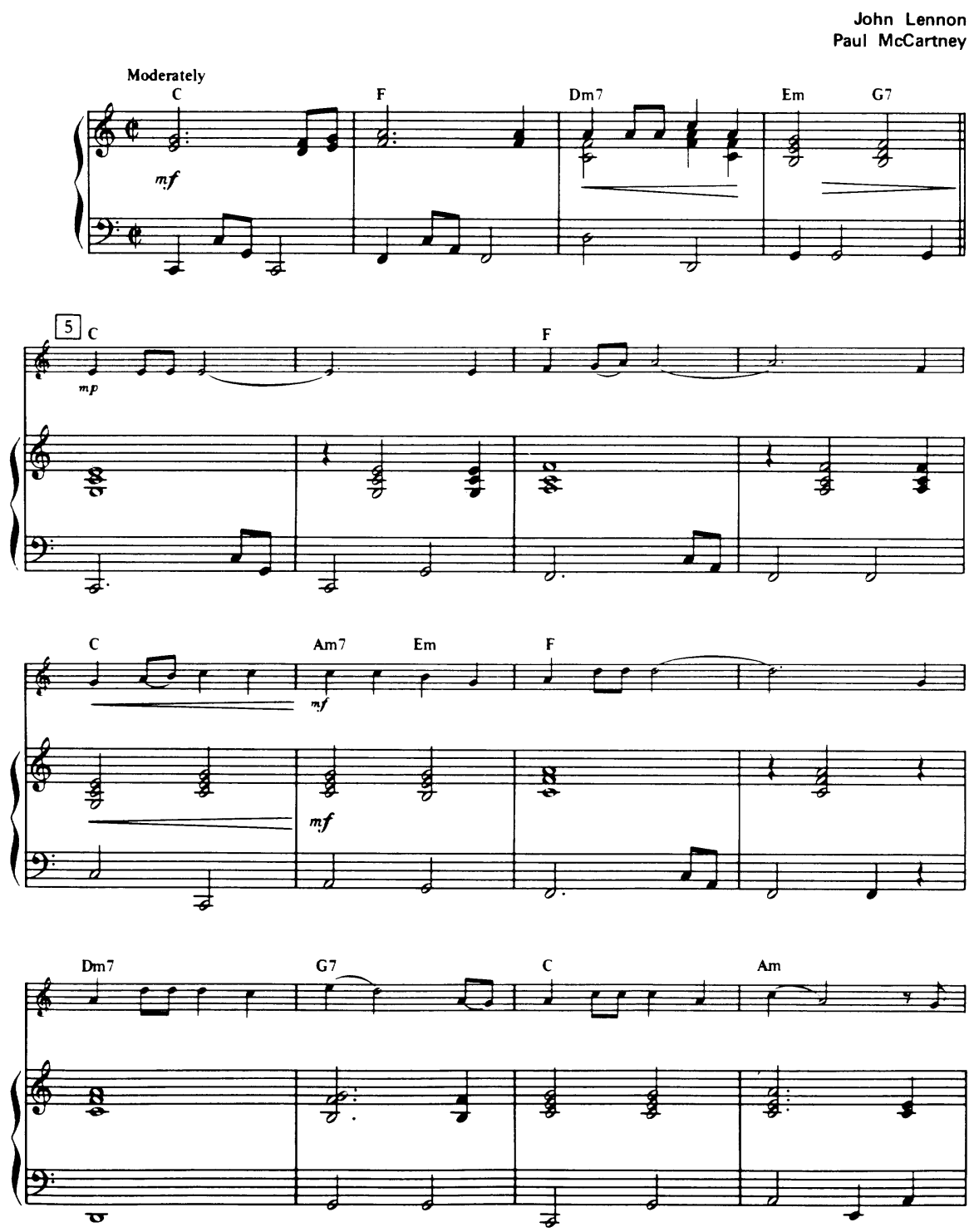

EXAMPLE 7

"THE FOOL ON THE HILL" (John Lennon and Paul McCartney) from Popular Flute arranged by Oran J. Daly, p. 12. (C)1967 by Northern Songs Ltd. All rights in the USA and Mexico controlled by Comet Music Corp., c/o ATV Music Corp. All rights reserved. Used by permission. 
Appendix B

Pretest and Posttest

\section{Forty Little Pieces}

in Progressive Order

for Beginner Flutists

Transcribed and adapted by Lou is Moyse

1. Ah! Vous dirai-je, maman

W. A. Mozit:
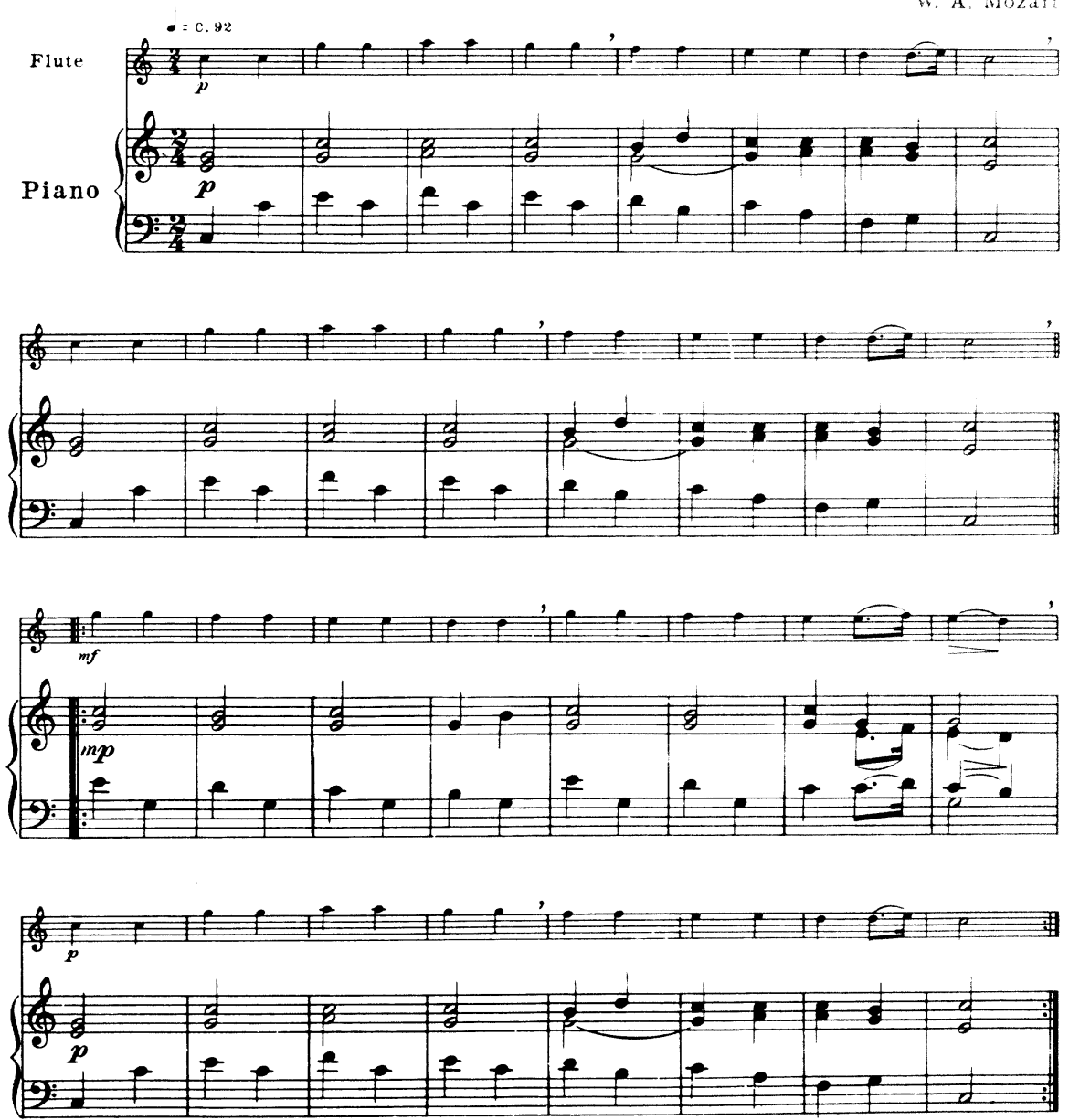

Pretest

"AH! VOUS DIRAI-JE, MAMAN" (W. A. Mozart) from Forty Little Pieces in Progressive Order by Louis Moyse, p. 2. (C)1966 by G. Schirmer, Inc. All rights reserved. Used by permission. 


\section{Scotch Dance}

Allegretto $d=$ c. 100

L. van Beethoven
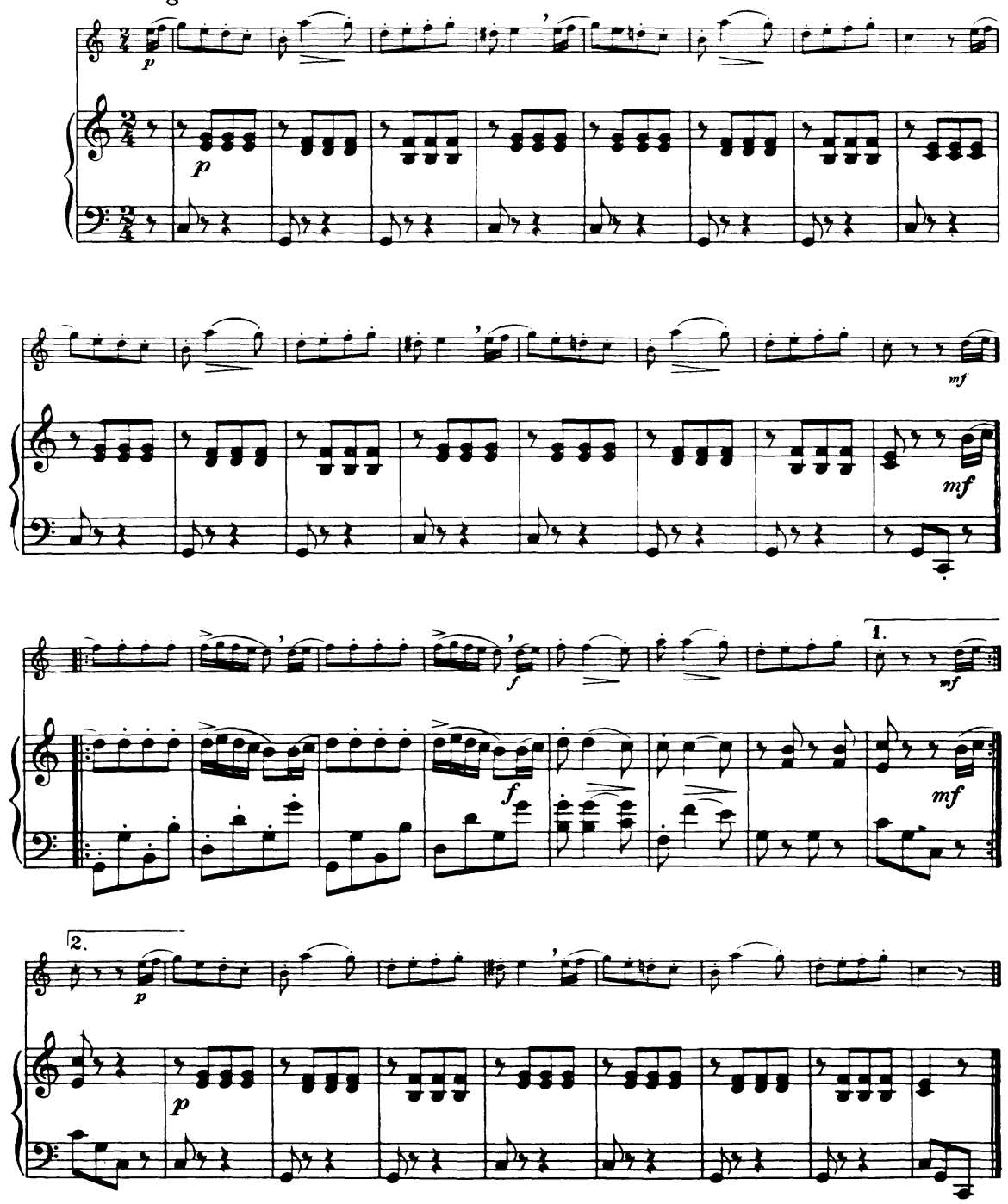

Posttest

"SCOTCH DANCE" (L. van Beethoven) from Forty Little Pieces in Progressive Order by Louis Moyse, p. 10. (C)1966 by G. Schirmer, Inc. All rights reserved. Used by permission. 


\section{Appendix C Scoring Directions}

The scoring procedure will be to score the student based on the number of errors that the student makes during the performance. The following types of errors will be evaluated: (1) pitch errors, (2) rhythm errors, and (3) expression errors. A description of each of the three types of errors is given below:

(1) Pitch Errors

Pitch errors constitute the following: (1) a note played on the wrong pitch, (2) a note omitted, or (3) a note that is repeated.

(2) Rhythm Errors

Rhythm errors constitute the following: (1) a note or rest that is not sustained long enough, or (2) a note or rest that is sustained too long.

\section{(3) Expression Errors}

Expression errors constitute the following: (1) failure to observe differences in dynamic indications, (2) failure to observe crescendo, decrescendo, accelerando and ritardando indications, (3) playing staccato notes legato, (4) playing legato notes staccato, or (5) playing non-legato under a slur.

For both the pretest and posttest the exact number of notes have been recorded on the scoring sheet. When the tape of the performer is played for the first time, the three adjudicators will circle on the musical score provided, any wrong notes they hear. They will then subtract the total wrong notes from the number of possible notes to gain the student's score on the note accuracy category of this test.

For both the pretest and posttest the exact number of beats have been recorded on the scoring sheet. When the tape of the performer is played for the second time, the three adjudicators will circle on the musical score provided, any wrong rhythms they hear. They will then subtract the total wrong beats from the number of possible beats to gain the student's score on the rhythm accuracy category of this test.

For both the pretest and posttest the following expression indications have been recorded on the scoring sheet: (1) any change in dynamics, (2) any staccato or legato indications, (3) any time the words crescendo, decrescendo, accelerando and ritardando appear, and (4) any time there are slur indications. When the tape is played for the third time, the three adjudicators will circle on the musical score provided, any expression marks that are not properly observed. They will then subtract the total errors from the number of possible expression marks to gain the student's score on the expression accuracy category of this test.

Because keyboard ability may vary student to student, not every student may be able to play the exact tempo indicated. Therefore, a tempo scale has been recorded on both the pretest and posttest scoring sheets. The three adjudicators will circle number three on the scale if the student plays the example at the indicated tempo. If the student plays the example too slow, the adjudicators will circle number one or number two on the scale to indicate the extent of deviation from the indicated tempo. If the student plays the example too fast, the adjudicators will circle number four or number five on the scale to indicate the extent of deviation from the indicated tempo. 